\title{
Smart Systems of Innovation for Smart Places: Challenges in deploying digital platforms for co-creation and data-intelligence
}

\begin{abstract}
The effect of digital transformation towards more efficient, place-based and bottom-up innovation policies at different spatial scales has proven significant, as digital technologies modify existing policy-design routines in cities and regions. Smart places (cities, districts, neighbourhoods, ecosystems) depend on the way digitalisation disrupts systems of innovation in cities, making it more open, global, participatory and experimental. We argue that the rise and interconnection of various types of intelligence (artificial, human, collective) could bring profound changes in the way smart places are being created and evolve. In this context, cyber-physical systems of innovation are deployed through multiple nodes acquiring digital companions, collaboration is deployed over physical, social, and digital spaces, and actors can use complex methods guided by software and get insights from data and analytics. The paper also presents the case study of OnlineS3, a two-year Horizon 2020 project, which developed and tested a digital platform composed of applications, datasets and roadmaps, which altogether create a digital environment for empowering the design of smart specialisation strategies for local and regional systems of innovation. The results indicate that digital transformation allows the operationalisation of multiple methodologies which have not been used earlier by policy makers, due to lack of capabilities. It can also increase the scalability of indicators facilitating decision making at different spatial scales and, therefore, better respond to the complexity of innovation systems providing dynamic and scale-diverse information.
\end{abstract}

Keywords: Systems of innovation; digitalisation; smart cities; intelligent cities; digital platforms; cocreation; data-intelligence

\section{Introduction}

A growing stream of literature suggests smart and intelligent cities stem from the connection between the digitalisation of systems of innovation and the spatial manifestation of digital platforms engaging actors of innovation (Schaffers et al., 2011; Cosgrave et al., 2011; Komninos, 2008; Tukiainen et al., 2015; Cohen et al., 2016; Anttiroiko, 2016; Komninos and Mora 2018; Mora and Deakin, 2019). Studies argue that the disruptive impact of digital technologies in cities takes place primarily on the supply and demand sides of innovation systems that drive change. Digital technologies and the Internet have modified routines that command daily working processes within cities, and thus, economy, everyday life, utilities and governance. The process can be represented by a chain of states which connects digitalisation, evolution of urban systems of innovation, changes in urban-related daily routines, optimisation of urban economy and life. In this understanding, smart places (cities, districts, neighbourhoods, ecosystems) depend upon the way digitalisation affects urban systems of innovation, making them more open, global, participatory and experimental.

The impact of digitalisation on systems of innovation is discussed in a very extended literature dealing with the contribution of digital technologies to innovation (Yoo, 2012; Barrett et al, 2015), changes in the innovation paradigm due to digitalisation (Baldwin and Von Hippel, 2011; Wu et al., 2015; Hinings et al., 2018), digital ecosystems for innovation (Oh et al., 2016; Komninos, 2013; Nachira et al. 2007), and the management of digital innovation (Yoo et al., 2012; Svahn and Henfridsson, 2012; Nambisan at al., 2017). The new landscape of innovation is shaped by the way systems of innovation merge in the Internet, resulting in the creation of cyber-physical systems in which collaboration networks, platforms, data and analytics sustain innovation processes, capabilities, and performance. 
This paper is placed at the intersection of the above-mentioned literature streams. It focuses on the relationship between smart cities and systems of innovation and looks into the challenges for digitally supporting local and regional systems of innovation, which in turn feed and sustain smart places. The questions that this paper seeks to answer include (a) What type of digital platforms and assistants would facilitate the processes of innovation at the local level?; (b) Which innovation processes could be improved and optimised?; (c) Which are the main barriers we need to confront during the design and development of digital platforms for innovation?; and (d) What is the level of user acceptance for digital environments sustaining innovation?.

Our enquiry into these questions is driven by a research hypothesis on connected intelligence. The main contribution of digital technologies and digital environments to innovation, and through it to smart cities and places, is related to connecting, human, collective, and machine intelligence. Connected intelligence is credited to interactive technologies, smart and intelligent systems, in which capabilities constructed by members interactions, with proper methods of aggregation, outperform capabilities of any member. The outcome refers to the combined intelligence of humans enhanced by collective intelligence of a community of people and organisations, as well as artificial intelligence enabled by data, hardware and software (Komninos, 2019; Komninos and Panori, 2019). In this regard, digital technologies and digital platforms enable connected intelligence to appear. They do it in two ways: on the one hand, by bringing many people together they allow collective intelligence to appear, and on the other, by using machine competences, such as memory, online collaboration, data analytics, object classification, forecasting, etc., they allow analytics and AI to further enhance human skills.

The use case presented in this paper is based on a two-year Horizon 2020 project called OnlineS3. This project made it possible to create and test a digital platform composed of a set of software applications, datasets, and roadmaps, which together form a digital environment for facilitating research and innovation strategies for smart specialisation. It offers some insights from a usability survey, assessing user behaviour and response to this digital platform. This paper is structured as follows. A literature review on critical aspects of innovation shaped by digital and cyber-physical spaces is presented in Section 2. Section 3 describes the challenges identified by the penetration of cyber-physical systems in the process of Smart Specialisation design. In Section 4 we discuss how innovation processes are optimized by user communities, co-creation, data-based intelligence, and software-based methodologies, as well as the major challenges in achieving such improvements in innovation systems, processes and policy.

\section{Smart technologies enhancing systems of innovation: Major instances}

The effect of digitalisation on systems of innovation can be traced down into many different areas, related to the creation of digital-physical (or cyber-physical) systems of innovation, as well as the optimisation of particular components of innovation (research, funding, producing, market making). It is produced by the immersion of systems of innovation into data systems and the creation of digital externalities. The impact of digitalisation on innovation is so wide and pervasive that gives birth to new product and service architectures (Yoo et al., 2010), introducing a paradigm shift (Song et al., 2009) that irreversibly transforms the entire economy (Brynjolfsson and McAfee, 2012).

The entanglement of innovation systems and digital systems takes place (a) during the design process of systems of innovation by using digital technologies, and (b) during the operation of systems of innovation within digital environments. It should be stressed that there is continuity and interdependence between the design phase and the operation phase of digital innovation environments, as the former defines areas of optimisation by digital means.

\subsection{Digital technologies and cyber-physical systems of innovation}

With the revision of the Mark II model of R\&D department-based innovation, proposed by Schumpeter (Scherer, 1986; Andersen, 2013; Dolfsma and Van der Velde, 2014) a common theoretical understanding has been achieved that prioritises networks and the external environment of innovation. Evolutionary 
theories assert that innovation springs from externalities, knowledge asymmetries, market imperfections, and institutions that select and manage flows of knowledge. Learning, as acquisition and use of existing knowledge, creation of new knowledge or conversion of tacit knowledge into explicit, is the key process. A specific cognitive space is created in each organisation composed of nodes and networks. The external environment has a decisive role also. Nelson and Winters (1982) argue that genetic processes to innovation are regulated by a 'selection environment' which switches on-off the flow between ideas and products. Nations and regions, through systems of innovation, provide this selection and regulatory environment, bridging knowledge, competences and resources from different actors and screening of ideas and technologies through competent or funding organisations (Nelson 1993). The ideas about the external environment of innovation have contributed to the 'open innovation' paradigm (Chesbrough, 2003) in which valuable ideas, knowledge and skills come from outside the organisation. Innovation becomes an "environmental condition" (Komninos, 2013); it is less an individual achievement than the joint effort of networks and communities of people working together, interacting, and sharing common skills and visions. Interactions within communities and institutions of innovation, combinations of roles and skills, communication channels, functional and spatial bonds bridging separate knowledge fields, and other participatory processes result in new products and technologies (Cooke and Morgan, 1997).

In this network-based innovation theory, different organisations and institutions work together to produce radical innovations. In incremental product development only, the innovation process is enclosed into a single organisation. Radical innovation tends to be systemic and network-based. In networks of innovation, the main actors are the financiers, providing funding suitable to innovation, research organisations, providing technology and competences, producers with their suppliers that undertake the product development, and brokers or market makers, creating / opening markets for new products, lead users, user communities and customers testing and assessing the new product, and government institutions safeguarding IPR or providing incentives to innovation (Radjou et al., 200; Dhanaraj and Parkhe, 2006; Piller and West, 2014).

When the above type of multi-actor innovation network meets with the Internet and the digital world, major transformations takes place, including (a) the explosion and multiplication of innovation actors (nodes) who participate with digital identities, (b) multiple forms of crowdsourcing, user engagement over crowdsourcing platforms or provision of funding by crowdfunding, (c) glocalisation of knowledge and specialisation by mixing local and global competence and know-how, (d) informed intelligence and discovery based on data, becoming available over the Internet, (e) skills improvement by digital tools and software for productivity, ideation, customer insight, and other. The outcome is a cyber-physical system of innovation in which all nodes acquire digital companions, collaboration is deployed over physical, social and digital spaces, and actors using complex product design and development methods guided by software and getting insights from data and analytics.

\subsection{User engagement, shared platforms, co-design and collective intelligence}

The transition of systems of innovation towards cyber-physical systems is linked to advantages created when digital interactions and e-tools are used in the processes of innovation. These advantages spread out at all stages of innovation, from ideation to product design, product launch, and commercialisation.

An area in which such advantages are documented is related to user engagement: user-driven innovation, co-design and experimentation with users, customer feed-back to product design, user experience design, crowdsourcing and living labs, are usual forms of user engagement facilitated by digital means and social media. These forms of engagement offer higher innovation efficiency and performance. They are discussed in a wide literature that clarifies the added value of user engagement to innovation (Bovaird, 2007; Baldwin and Von Hippel, 2011), the forms of user engagement (Mahyar at al. 2015), methods of co-design with users (Susha et al., 2015; Sanders and Stappers, 2008), use of crowdsourcing and shared platforms (Georges at al., 2015; Seltzer and Mahmoudi, 2013). 
Main drivers of advantages offered by user engagement to innovation are creativity and collective intelligence. Many organisations use crowdsourcing to get fresh ideas into their innovation process. With crowdsourcing a task once performed by one or a few persons is outsourced to a large, undefined group of people external to the organisation. The goal is to harness the creativity and ingenuity of many (Aitamurto et al., 2011; Djelassi and Decoopman, 2013) and increase the probability of generating original ideas by increasing the number of individuals that participate in ideation. In more complex forms of crowdsourcing, organisations introduce community-based sessions in which members of a community participate in focused idea generation. These sessions centre on a specific topic and last for a relatively short amount of time (Bayus, 2013). The assumption behind it is that team collaboration can release collective intelligence and reduce fixation effects (Sharma, 2010; Qi et al., 2013).

\subsection{Software and data-driven innovation}

Innovation within digital environments is also enhanced using digital tools and datasets in the pursuit of a particular innovation path. An extensive survey on the use of digital tools in innovation processes highlights how top R\&D companies use digital tools, analyse usage data, and simulate user experience to improve the usability and serviceability of products (Jaruzelski et al., 2013). The survey shows that digital tools are being used at all stages of innovation, from collecting and analysing user insights, generating ideas, designing and manufacturing new products, to tracking the success of products. Many e-tools focus on creating conditions to improve the front-end of innovation (idea generation, technology insights, and concept development stages) where innovations are produced by the engagement of customers and users.

Different tools are used per innovation stage. In the insight stage, discussion platforms, customer profiling, and big data analytics; in the ideation stage, co-design, rapid prototyping, and crowdsourcing; in the development stage project management software, $\mathrm{CAD}$, and collaborative environments; in the launch stage, CRM, ERP, and social media dashboards. A general trend is the transition from productivity tools towards market creation and commercialization tools that engage users and customers. The market perspective becomes dominant with customer immersion labs and customer profile analysis, which allow companies to gather data and feed-back on new product designs from individuals. Digitally simulated environments are used in product design, and data analytics allow companies to collect and analyse data from customers using automated tracking technologies. In the field of productivity tools, the most effective are becoming 3D modelling and rapid prototyping, which enable a substantial reduction in product development time and cost.

Innovation by digital means in knowledge-intensive services leads to similar conclusions. A deeper knowledge framework is needed, which is co-produced and shared with customers (Walsh, 2014). Design and development projects sustained by digital technology and tools, such as online public participation and involvement of users, modify the classic 'top-down' innovation approach into a more open and interactive process (Deakin et al. 2017; 2018).

\subsection{Glocalisation of knowledge, place-based innovation and smart specialisation}

The rise of cyber-physical systems of innovation and the advantages offered by user engagement and crowdsourcing mediated by technology, software guided e-tools, datasets and analytics change the way local capabilities, knowledge and human capital is connected to global knowledge flows. The glocalization of innovation systems is driven by increasingly complex, non-linear and dynamic processes of knowledge creation, diffusion and use. To capture this complexity, Carayannis and Campbell (2009) proposed the concept of "Mode 3 Innovation Ecosystem", at the intersection of 'Innovation Networks' and 'Knowledge Clusters": "This is a multi-layered, multi-modal, multi-nodal and multi-lateral system, encompassing mutually complementary and reinforcing innovation networks and knowledge clusters consisting of human and intellectual capital, shaped by social capital and underpinned by financial capital".

In Europe, the concept of smart specialization is getting close to the above understanding of convergence between innovation networks, global knowledge flows and local clusters (Carayannis and Rakhmatullin, 
2014). In the smart specialisation perspective, the European cities and regions should explore and exploit key capabilities for global niche markets, with the intention of creating long term competitive advantages (Foray, 2014; Reid and Maroulis, 2017). Thus, the overall objective is to create innovative, but place specific, capabilities which take advantage of available resources and competences within a process of diversification and transformation.

Smart specialisation is based on a series of principles (Landabaso, 2014; Rodriguez-Pose and Wilkie, 2017) such as the place-based approach, which builds on local available resources in order to explore and exploit entrepreneurial opportunities for economic growth; the evidence-driven decision-making, focusing on few but well-identified priorities for smart knowledge-based investments to strengthen competitive potentials; the interactive stakeholder engagement and intelligence gathering that supports the entrepreneurial discovery processes for setting priorities bottom-up; and the solid monitoring and evaluation, including effective and efficient revision mechanisms should allow flexible adoption of strategic decision making. To a large degree these conditions can be fulfilled into cyber-physical systems of innovation only by the augmentation roles of data, software, and online communication.

\section{Challenges in cyber-physical systems of innovation: Learning from a case study}

Digitalisation, the formation of cyber-physical systems of innovation, and their impact on innovation performance and glocalisation of innovation are creating a new landscape for innovation. Thus, it is essential to acquire a better understanding of the convergence between innovation systems and digital systems, both at the level of strategy development and systems operation. In this regard, the design and development of the Online S3 platform (www.s3platform.eu) and the survey on its usability can offer some useful insights on challenges and barriers we confront in developing digital environments for innovation and how they contribute to local and regional systems of innovation.

\subsection{The role of digital transformation, co-creation and data in the design of S3 strategies}

Smart specialisation strategies (RIS3) rely on an inherently complex design process that by definition builds on multi-actors' interactions, encompassing an essential number of activities and interactions, such as pilot testing, extended monitoring and assessment and stakeholders' participation (Rowe and Frewer, 2004; Charalabidis et al, 2010; Komninos et al, 2014; Panori et al, 2016). Moreover, the growth challenges of smart specialisation are often characterized by uncertainty and ambiguity, including not only disagreements within society, but also power games between interest groups (Bütschi, 2012). They require multidisciplinary knowledge, transparency and a plurality of values and opinions. Throughout the design of RIS3, policymakers and practitioners should become proactive, develop evidence-based and user-driven attitudes, whilst build internal institutional capabilities to manage technologies, information and user engagement. (Komninos et al., 2018)

At the same time, data collection and analysis have emerged as valuable features for exploring and leveraging existing spatial structures, networks and potential niche market opportunities in smart places (i.e. cities, regions, ecosystems). Digital transformation in this sense is able to produce novel types of information which are essential for effectively design strategies towards strengthening place-based or mission-oriented developmental paths (Panori et al., 2018). More specifically, digital platforms act as shared spaces where the effects of data analysis and co-creation can be effectively released and disseminated to a broad range of actors.

This fast-paced transition to platform-based ecosystems has been transformed from a "disruptive innovation" to, what is today, an essential feature of smart places (including smart cities and regions). Thus, it has significantly affected the evolution of systems of innovation and the design of strategies for strengthening their effectiveness (Angelidou et al, 2011; Komninos, 2014; EC, 2015; Angelidou et al, 2017; Panori et al, 2017). The creation of new opportunities for stakeholder participation and collaboration, as well as knowledge discovery through data analysis are features offered by digital spaces (Komninos and Panori, 2019), whereas at the same time they are also fundamental aspects of smart specialisation. Hence, 
platforms can act as knowledge facilitators (Langlois and Elmer, 2013; van Dijck, 2013; Schwarz, 2016) offering a connected intelligence environment for smart specialisation processes to be undertaken, strengthening evidence-based decision-making.

\subsection{The OnlineS3 Platform and the road to Smart Specialisation 2.0}

All new industrial and innovation policies - including policies for smart specialisation - share certain characteristics that confine them to the sphere of the private sector, actors of an innovation system, and markets in general (Radosevic, 2017). Smart specialisation was originally conceived as an entrepreneurial discovery process (EDP) that would involve regions in a learning process resulting in decision on novel development paths (Foray et al., 2009). Through the EDP, smart specialisation has proved to be quite successful in encouraging stakeholders' interaction, widening their participation, enabling more efficient functioning of multi-level governance, as well as enabling continuity of the process of planning and implementation of a regional innovation strategy (Gianelle et al., 2016; Kleibrink and Edurne, 2018). However, societal stakeholders are not as involved in EDP as they should be (Marinelli and Perianez Forte, 2017) limiting the potential of collaborative knowledge production in these policies in terms of prioritisation. Smart specialisation should ideally be more integrative among R\&D-driven innovation policy, cohesion policy, European value chains and networking initiatives, industrial policy, as well as grand policy challenges (Foray et al., 2018). This is consistent with mission-oriented policies in the field of R\&I that should have societal relevance and be multi-sectoral in nature (Mazzucato, 2018). That way smart specialisation could expand the boundaries of its current scope and scale by more effectively encompassing benefits related to collaborative intelligence.

In this framework, the design of S3 in the coming programming period 2021-2027 (Smart Specialisation 2.0 ) will be guided by the pursuit of good governance. The concept of governance "is broadly conceived as a form of coordination in the taking of collectively binding decisions within a certain community" (Beunen et al., 2015, p.4). At the same time, the term governance is regularly connected with a shift from the idea of government to governance, which refers to a gradual transition from a central expert-driven management model to more participatory forms of decision-making (Beunen et al., 2015). In this regard, good governance in the case of Smart Specialisation 2.0 should be based on seven enabling conditions, defined by the 2021-27 Cohesion Policy objective for 'a Smarter Europe' through innovation, digitisation, economic transformation and support to small and medium-sized businesses. These are: (1) analysis of challenges including bottlenecks for innovation diffusion; (2) existence of competent regional/national institution or body, responsible for the management of the smart specialisation strategy; (3) monitoring and evaluation tools to measure performance towards the objectives of the strategy; (4) effective functioning of entrepreneurial discovery process; (5) actions to improve national or regional research and innovation systems; (6) actions to manage industrial transition; and (7) actions for internationalisation. Aligned to the concept of governance, these seven conditions should be achieved by participatory processes, user and stakeholder engagement.

In tandem, the same enabling conditions require information-intensive environments and access to up to date datasets. This is pertinent for the assessment of innovation bottlenecks, the deployment of monitoring and evaluation tools, the effective entrepreneurial discovery process, as well as the actions towards industry 4.0 solutions, Artificial Intelligence (AI) and big data analytics in all priority industries. Throughout the Entrepreneurial Discovery Process (EDP), which is considered as a key enabling condition, different entrepreneurial actors are brought together in a government-led participatory process generating a collective debate, integrating the divided and dispersed knowledge belonging to different actors, and setting common priorities for intervention (Foray et al., 2012). The aim is to build a systematic understanding of the areas in the economy and society that have the greatest potential for future development and resolve the difficult problem of activities prioritisation and resource allocation. Therefore, EDP should be performed at a satisfactory level of granularity, assuring that productive features and regional context are well assessed in the design of priorities and actions. 
The enabling conditions of Smart Specialisation 2.0 for the 2021-2027 period focusing on good governance require both large-scale user and stakeholder engagement and rich datasets and analytics. The use of digital tools, assistants, online environments and data analytics becomes a prerequisite as far as the demand for quality S3 design raises and the needs for up to date datasets and complex analytics methods for assessing future regional developmental potential and opportunities intensify.

Given the complexity in the design and implementation of smart specialisation strategies, the OnlineS3 project has been set out to develop a platform-based solution to facilitate the creation of a user-friendly environment with easy access to datasets and complex methodologies, whilst targeting on strengthening multi-user interactions. This has been achieved through the development of 28 applications covering all the proposed phases of strategy development, proposed by Foray et al. (2012) (Fig.1). The OnlineS3 Platform constitutes an experiment of reference towards empowering strategy development through cyber-physical systems of innovation for several reasons. First, it focuses on providing an online shared space for managing the design process of a smart specialisation strategy. Second, it tries to foster effective online collaboration and co-creation between different actors, offering the opportunity to include a wide range of participants. Third, it ensures equal access to existing datasets and design methodologies (simple or more sophisticated), since all tools are freely available and open access. Thus, it aims at triggering collaborative and artificial intelligence externalities.

Figure 1: The OnlineS3 Platform mechanism for smart specialisation strategy design and implementation

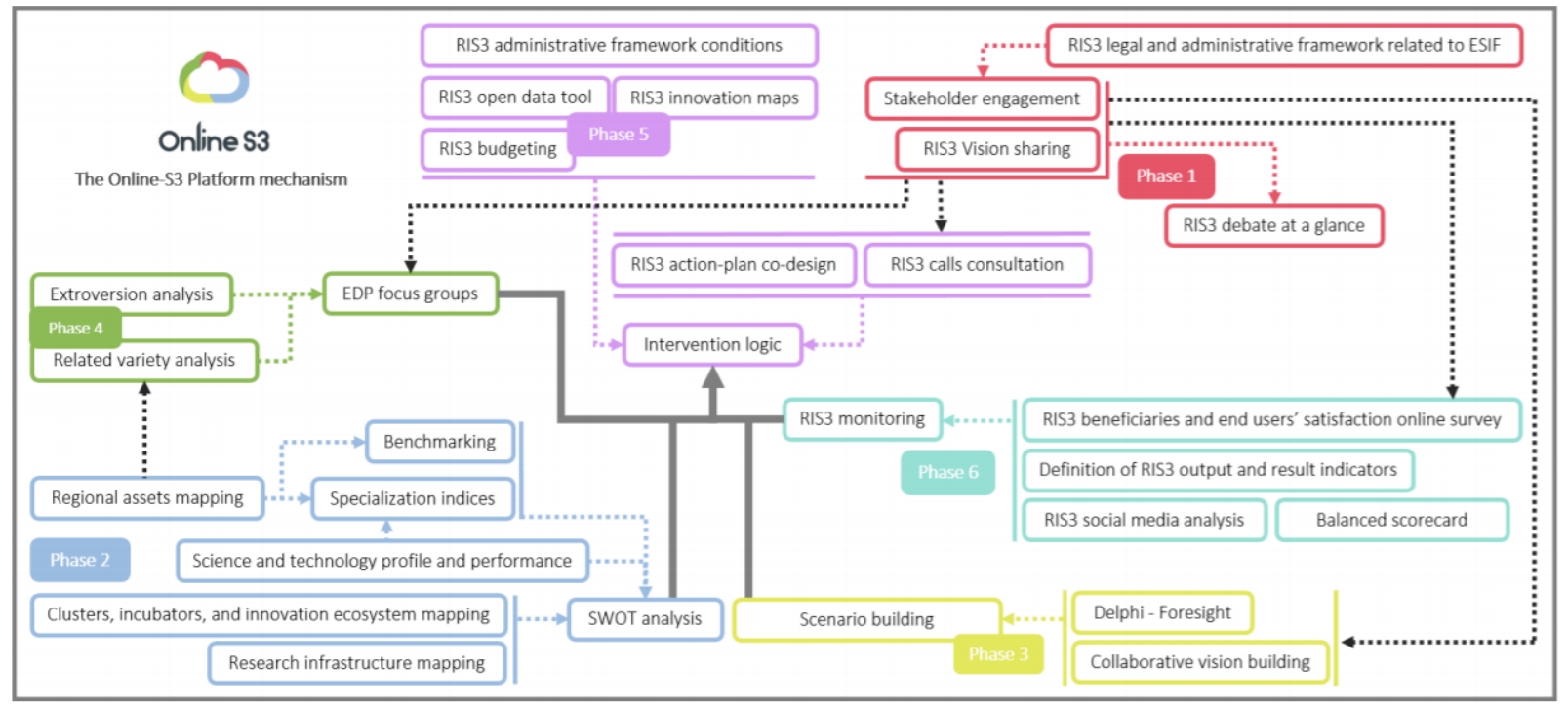

The OnlineS3 Platform promotes a sharing knowledge model through cyber-physical systems of innovation for smart growth. Under this context, it offers a peer exchange and learning space that triggers potential innovative interactions between sectors and regions, which may lead to disruptive synergies, acting as boosters for smart growth perspectives. Through this process OnlineS3 aims at creating innovative placespecific capabilities through the glocalisation of knowledge, which take advantage of available resources and competences within a process of diversification and transformation. This paves the way for a next phase in smart specialisation where the EDP will be accompanied by a continuous regional discovery process. Under this context, cyber-physical systems of innovation will act as essential instruments for empowering connected intelligence aspects, including collaborative and artificial intelligence, as well as glocalisation of knowledge, paving the way for Smart Specialisation 2.0.

\subsection{How a digital transformation of the innovation strategy is produced?}

Our main argument in this paper is that digital transformation of an innovation strategy is enhanced using digital tools and datasets in the pursuit of identifying an optimised innovation path for a smart place. 
Regions and cities have been experiencing essential transformations during the last decades, by applying innovative approaches to problem-solving and governance paradigms. The adoption of smart systems and technologies follows a process that connects theoretical frameworks, methodological approaches and best practices, coming from diverse fields of research, such as informatics and engineering, planning and development, economics and innovation management. In this regard, the term 'smart' or 'intelligent' has been mainly used to describe an augmented governance model for promoting development in a place, where traditional and disruptive elements co-exist and interact.

Following the efforts that have been made to investigate the creation of intelligence in smart places (Kitchin, 2014; Kummitha and Crutzen, 2017; Mehr et al., 2017; Mora and Bolici 2017; 2018; Mora et al. 2017; 2019a; 2019b), the OnlineS3 experiment has indicated that spatial 'smartness' emerges from the integration of different interconnected types of digital transformation and multi-level governance. These refer to: (i) human intelligence, referring to aspects of inventiveness, creativity and intellectual capital of the population; (ii) artificial intelligence, provided by public infrastructure, virtual and smart environments; and (iii) collective intelligence, produced by relevant actors and institutions, relying on rules for collaboration and social capital (Komninos, 2008). It becomes evident that 'smartness' of a place is based on informational and cognitive processes, such as information collection and processing, real-time alert, evidence-based decision-making, forecasting, learning, awareness, distributed problem-solving, cocreation and collaborative innovation that take place throughout the design of innovation strategies (Komninos, 2018; D’Onofrio et al., 2019; Tabacchi et al., 2019; Komninos and Panori, 2019).

The main objective of the OnlineS3 platform has been to enhance the emerging properties of smart specialisation through sustaining research and innovation, as well as organising knowledge production, data analysis and co-creation. In this way, it has become possible to act as a platform of reflexive control regarding the priorities set by smart specialisation processes, towards effectively supporting their monitoring, evaluation and adaptation to new challenges. Hence, it is formed as a 'space' where actors and artifacts co-exist, communicate and exchange knowledge and capabilities, leading to cyber-physical systems and co-creation of innovation (Giovannella, 2013). Organised knowledge production and democratisation of the knowledge economy are two additional features offered by the OnlineS3 platform that play a key role in the digital transformation of the innovation strategy process. Moreover, further processes can be identified for optimizing these integrated multidimensional activities, towards empowering smart places to exploit their full potential (Streitz, 2017).

\subsection{OnlineS3 Platform assessment: Results from the usability survey}

In order to investigate the effects of the OnlineS3 platform on the road to Smart Specialization 2.0, we performed a usability survey results from different stakeholders who used the OnlineS3 applications during the project lifetime. We chose to approach user perceptions including the dimensions of 'usefulness', 'level of satisfaction' and 'ease of use' (Lund, 2001; Rojas and Macías, 2013). This work is based on results from previous (online) policy and innovation research processes (Abelson and Gauvin, 2006; Rowe and Frewer, 2004, 2005), emphasising that successful stakeholder participation is characterized by an interplay of quality dimensions which enable better design of public participatory processes for new online services.

The sample includes a set of 686 individuals that responded in a short questionnaire focusing on the OnlineS3 applications, conducted from November 2017 to February 2018, covering four regions: Eastern Scotland (UK), Central Macedonia (Greece), Northern Netherlands (the Netherlands) and Galicia (Spain). All participants were identified through stakeholder engagement strategies in each region and participated in the workshops that have been organised by project partners. Fig. 2 provides an overview of the assessment of each application based on the engaged stakeholders who were able to evaluate each application from a scale from 1 (very good) to 5 (very poor) by answering the following questions: (1) How user-friendly is this application? (user-friendliness); (2) How useful is this application? (usefulness); and (3) How likely are you to use this application in future? (future application potential). 
In order to get a better understanding of user perceptions in the different areas covered by the OnlineS3 areas of intervention, we choose to group the 28 applications in four discrete categories: (i) collaborative production, including all applications promoting multi-stakeholder interactions (e.g. action plan co-design, collaborative vision building, stakeholder engagement); (ii) data processing, which refers to all applications using data analysis as their main functionality to derive useful outcomes (e.g. regional assets mapping, benchmarking, related variety); (iii) information sharing, including applications targeting on collecting and sharing data to users from multiple data sources (e.g. RIS3 legal and administrative framework, research infrastructure mapping, RIS3 calls consultation); and (iv) monitoring and evaluation, referring to applications for empowering these areas (e.g. definition of RIS3 output and result indicators, RIS3 monitoring, balanced scorecard).

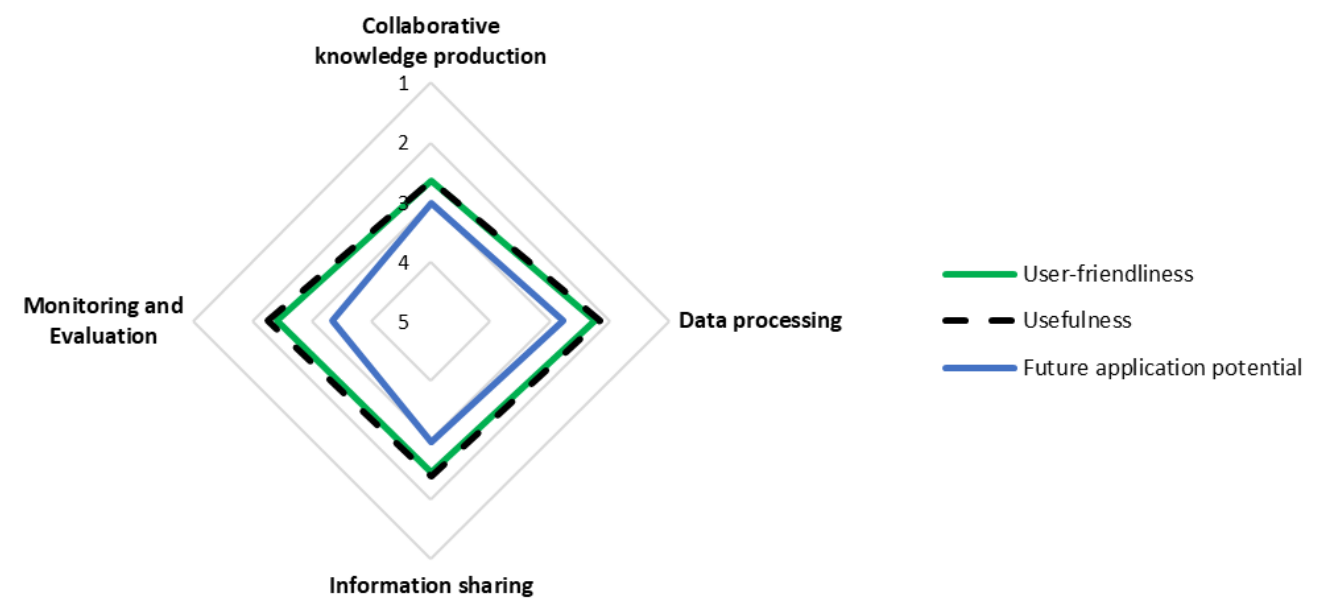

Figure 2: Stakeholders' assessment of the different categories of Online S3 applications (Source: OnlineS3 usability survey short questionnaires) Note: Sample size: 673 questionnaires, Assessment scale from 1 (very good) to 5 (very poor).

The results indicate that the OnlineS3 applications have received positive feedback overall, as in both userfriendliness and usefulness categories the overall assessment is above average. However, there seems to be a neutral perception in terms of future application potential, meaning that the users do not seem so positive about whether they will use these applications in the future. Data processing, information sharing, monitoring and evaluation categories have received higher scores when compared to collaborative knowledge production. This might be either due to the higher need for data-related applications, or to existing difficulties when trying to boost collaborative production and stakeholder engagement during decision-making processes.

In general, the OnlineS3 applications have positively affected perceived satisfaction in terms of userfriendliness and usefulness, throughout the overall design process of RIS3. From a practical perspective, this means that the more stakeholders are informed and engaged online via such tools, the higher the stakeholder satisfaction regarding their participation in the RIS3 policy-design process. This is in line with theoretical background stating that receiving enough information can lead to a better decision-making process (Schmidt and Spreng, 1996; Chen and Chang, 2003; Karimi et al., 2015). Therefore, OnlineS3 platform provided a basis for further exploiting the potential of applying cyber-physical systems on the design and development of smart specialisation policies, towards strengthening the idea of shared digital spaces in smart places, such regions or cities.

\section{Challenges in deploying digital platforms for co-creation and intelligence}

The bulk of the recent literature on digital platforms and the case study used in this paper, both highlight the effect of online tools and digital assistants towards more efficient, place-based and bottom-up innovation policies at different spatial scales. The benefits that arise from their development and use are 
immense and they span from the increased participation in knowledge-based policy design and the emergence of collective intelligence to the ICT-assisted creation, collection, visualisation and use of an enormous amount of data and the consequent increase of data-intelligence. We argue that the rise and interconnection of these two types of intelligence could bring profound changes in the way smart places (cities, regions) are being created and evolve.

\subsection{Platform-based co-design and collective intelligence in innovation policy space}

Digital platforms, tools and assistants can leverage individual intelligence towards specific areas of policy making. They provide a means to wider engagement and collaboration empowering policy makers to reach decisions that are better and of wider consensus. Their effect on engagement and participation in decision making facilitates an increase in transparency triggering additional levels of interaction and, therefore, improving the overall effectiveness of a policy. An interesting aspect is that everyone is included, regardless of their background/knowledge base. The assessment study on OnlineS3 tools for smart specialisation policy design and implementation has shown that these have been considered useful even to actors that did not have a prior experience related to the specific policy area. In terms of engagement, all types of stakeholders from the quadruple helix were involved: business, research, government and civil society.

An increase in the use of digital platforms and tools can have a wider effect than the mere digital collaboration and the emergence of collective intelligence; their impact can be and lead to transformative changes of the innovation system itself. Depending on their focus area, most digital tools and platforms (skills development platforms, marketplaces, open data repositories, collaboration platforms) produce proximity effects in the digital space, similar to those deriving by spatial proximity, facilitating the formation of smart ecosystems. Besides their direct benefits that are linked to their original development purpose, the aggregation of many digital platforms/tools interacting with a diverse set of actors from the physical space (citizens, users, businesses, organisations, governments) drive an explosion of (digital) externalities in parallel to the physical networks, interactions and externalities, "augmentifying", thus, the spillover effects in an economy (Komninos, 2019; Komninos and Panori, 2019).

\subsection{Platforms, data-based intelligence, and the next stage of Smart Specialisation Policy}

As described at the beginning of our paper, recent literature has shown that the on-going data revolution and data intelligence are increasingly evident in innovation creation and business decisions but not yet in policy making. However, spatial innovation systems are complex systems composed of many components which dynamically interact, highlighting the need for more timely and dynamic data sources. We argue that open and big-data driven policies can better track and forecast economic activity, secure a higher level of frequency and granularity compared to traditional survey data, create proxies of economic indicators and contribute to more accurate analysis of an innovation system.

All these advancements can be extremely useful at the policy level. Besides, designing place-based global oriented strategies, presupposes an understanding of the digital drivers for economic transformation through new areas for diversification, new ways of knowledge diffusion, collaboration and value creation. Within the smart specialisation paradigm for example, European cities and regions should create place-based strategies by exploring and exploiting key capabilities for global niche markets with the intention of creating long term competitive advantages. To complete this task, they should be aware of their competitive assets compared to other regions and be able to identify niche markets and disruptive industry trends. In addition to these tasks, they should be able to identify (possibly in neighbouring places) skills' sources for new areas of diversification. In many cases, they should also be able to identify their position in Global Value Chains (GVCs) in order to try to disrupt the chain through better positioning. All these seem quite daunting especially considering that regions and cities mainly rely to statistical data of limited variety and comparability. Data are mostly collected at predetermined/administrative spatial boundaries, loosing thus information on dynamics and interdependencies at the intersection of different spatial scales. 
Through our case study we have shown that digital tools and assistants allow the operationalisation of multiple methodologies that cannot be used by policy makers due to lack of capabilities. They can also increase the scalability of indicators facilitating decision making at different spatial scales and, therefore, better respond to the complexity of innovation systems providing dynamic and scale-diverse information. Tools can be combined in multiple ways building-up new insights or create input for new tools/methods of analysis. Most importantly, the enormous amount of possibilities that such tools unlock, combined with the power of policy makers but also of groups of individuals, institutions and actors of the innovation process, enable new processes and interactions of (potentially) higher quality which definitely more informed and knowledge-empowered. The rise of such connected intelligence creates a profound impact on the design, operation and transformation processes of smart cities and smart places.

The wider implications of supporting policy-making by online platforms and digital tools is about providing the conditions for effective policy design and implementation. A policy vision is not sufficient unless the conditions of implementation are provided. This an important lesson learnt during Smart Specialisation 1.0. Our survey and mapping on RIS3 design in 30 EU strategies ( 9 at national level and 21 at regional level) showed significant diversions from the RIS3 principles, even in the wealthiest and most innovative regions. These are related to weak stakeholder engagement and information dissemination methods promoting engagement and participatory decision-making; identification of priorities was based on working/focus groups, but very few participatory deliberation and collaborative design of actions and annotation of opportunities were followed; very limited use of output and result indicators as most prevalent monitoring method; many of the described approaches seemed simplistic for an comprehensive and effective monitoring and impact assessment (Griniece, et al., 2017; Komninos et al., 2019).

The Smart Specialisation exercises during 2014-2020 introduced an ambitious vision for place-based and evidence-based research and innovation policy, but the methodological support and preparation for implementation were not at the level of the policy ambition. The pilot testing of Online S3 showed that stakeholders were eager to use online assistants, software supported methods, web databases, and tools for digital engagement. Their critique was on the completeness and friendliness of applications and online methods rather than the usage of digital environments for policy making. With the advent of Smart Specialisation 2.0 and the increasing demand for high quality and effective governance, and in light of the seven enabling conditions of good governance for 'Smarter Europe', offering methodologies and datasets for effective policy design and implementation is a prerequisite for optimal policy design and management.

\section{References}

Abelson, J., \& Gauvin, F. P. (2006). Assessing the impacts of public participation: Concepts, evidence and policy implications. Ottawa: Canadian Policy Research Networks.

Aitamurto, T., Leiponen, A., \& Tee, R. (2011). The promise of idea crowdsourcing-benefits, contexts, limitations. Nokia Ideasproject White Paper, 1, 1-30.

Andersen, E. S. (2013). Schumpeter's core works revisited. In Long Term Economic Development (pp. 931). Springer, Berlin, Heidelberg.

Angelidou, M., Gountaras, N., \& Tarani, P. (2011). Digital services in knowledge cities: the case of digital Thermi. 4th Knowledge Cities World Summit, 26-27.

Angelidou, M., Psaltoglou, A., Komninos, N., Kakderi, C., Tsarchopoulos, P., \& Panori, A. (2018). Enhancing sustainable urban development through smart city applications. Journal of Science and Technology Policy Management, 9(2), 146-169.

Anttiroiko, A. V. (2016). City-as-a-platform: The rise of participatory innovation platforms in Finnish cities. Sustainability, 8(9), 922.

Baldwin, C., \& Von Hippel, E. (2011). Modeling a paradigm shift: From producer innovation to user and open collaborative innovation. Organization Science, 22(6), 1399-1417.

Barrett, M., Davidson, E., Prabhu, J., \& Vargo, S. L. (2015). Service innovation in the digital age: key contributions and future directions. MIS quarterly, 39(1), 135-154. 
Bayus, B. L. (2013). Crowdsourcing new product ideas over time: An analysis of the Dell IdeaStorm community. Management science, 59(1), 226-244.

Bettman, J. R., \& Park, C. W. (1980). Effects of prior knowledge and experience and phase of the choice process on consumer decision processes: A protocol analysis. Journal of consumer research, 7(3), 234248.

Beunen, R., Van Assche, K., \& Duineveld, M. (2015). Evolutionary Governance Theory. Springer.

Boden, M., Marinelli, E., Haegeman, K., \& Dos Santos, P. (2015). Bridging thinkers and doers: first policy lessons from the Entrepreneurial Discovery Process in Eastern Macedonia and Thrace (No. JRC96584). Joint Research Centre (Seville site).

Bovaird, T. (2007). Beyond engagement and participation: User and community coproduction of public services. Public administration review, 67(5), 846-860.

Brynjolfsson, E., \& McAfee, A. (2012). Race against the machine: How the digital revolution is accelerating innovation, driving productivity, and irreversibly transforming employment and the economy. Brynjolfsson and McAfee.

Bütschi, D. (2012). Knowledge based policy making, Report on the First Parliamentary TA Debate held in Copenhagen on June 18th, 2012.

Carayannis, E. G., \& Campbell, D. F. (2009). 'Mode 3'and'Quadruple Helix': toward a 21st century fractal innovation ecosystem. International journal of technology management, 46(3-4), 201-234.

Carayannis, E. G., \& Rakhmatullin, R. (2014). The quadruple/quintuple innovation helixes and smart specialisation strategies for sustainable and inclusive growth in Europe and beyond. Journal of the Knowledge Economy, 5(2), 212-239.

Charalabidis, Y., Gionis, G., Ferro, E., \& Loukis, E. (2010). Towards a systematic exploitation of web 2.0 and simulation modeling tools in public policy process. In International Conference on Electronic Participation (pp. 1-12). Springer, Berlin, Heidelberg.

Chen, S. J., \& Chang, T. Z. (2003). A descriptive model of online shopping process: some empirical results. International Journal of Service Industry Management, 14(5), 556-569.

Chesbrough, H. (2003). Open Innovation. The New Imperative for Creating and Profiting from Technology. Harvard Business School Press

Cohen, B., Almirall, E., \& Chesbrough, H. (2016). The city as a lab: Open innovation meets the collaborative economy. California Management Review, 59(1), 5-13.

Cooke, P., and Morgan, K. (1997). The Associational Economy: Firms regions and innovation. Oxford University Press.

Cosgrave, E., Arbuthnot, K., \& Tryfonas, T. (2013). Living labs, innovation districts and information marketplaces: A systems approach for smart cities. Procedia Computer Science, 16, 668-677.

Deakin, M., Mora, L., \& Reid, A. (2017). Smart Specialisation Strategies in the Post-linear Era on Research and Innovation. In P. Ketikidis, \& A. Solomon (Eds.), 10th International Conference for Entrepreneurship, Innovation, and Regional Development (ICEIRD 2017): University-Industry Links: Coproducing Knowledge, Innovation \& Growth. Conference Proceedings, Thessaloniki, 31 August - 01 September 2017 (pp. 529-540). Sheffield: The University of Sheffield and SEERC.

Deakin, M., Mora, L., \& Reid, A. (2018). The Research and Innovation of Smart Specialisation Strategies: The Transition From the Triple to Quadruple Helix. In M. Bozina Beros, N. Recker, \& M. Kozina (Eds.), 27th International Scientific Conference on Economic and Social Development: Book of Proceedings, Rome, 1-2 March 2018 (pp. 94-103). Varazdin: Varazdin Development and Entrepreneurship Agency.

D’Onofrio, S., Papageorgiou, E., \& Portmann, E. (2019). Using Fuzzy Cognitive Maps to Arouse Learning Processes in Cities. In Designing Cognitive Cities (pp. 107-130). Springer, Cham.

Dhanaraj, C., \& Parkhe, A. (2006). Orchestrating innovation networks. Academy of management review, 31(3), 659-669.

Djelassi, S., \& Decoopman, I. (2013). Customers' participation in product development through crowdsourcing: Issues and implications. Industrial Marketing Management, 42(5), 683-692.

Dolfsma, W., \& Van der Velde, G. (2014). Industry innovativeness, firm size, and entrepreneurship: Schumpeter Mark III?. Journal of Evolutionary Economics, 24(4), 713-736. 
European Commission. (2015). Online Platforms and the Digital Single Market Opportunities and Challenges for Europe. Brussels, May 2016.

Foray, D., (2014). From smart specialisation to smart specialisation policy. European Journal of Innovation Management 17(4), 492 - 507.

Foray, D., David, P. A., \& Hall, B. (2009). Smart specialisation-the concept. Knowledge economists policy brief, 9(85), 100.

Foray, D., Goddard, J., Beldarrain, X. G., Landabaso, M., McCann, P., Morgan, K., Nauwelaers, C., and Ortega-Argilés, R. (2012). Guide to Research and Innovation Strategies for Smart Specialization (RIS3). Luxembourg, Publications Office of the European Union.

Foray, D., Morgan, K. and Radosevic, S. (2018). The role of smart specialisation in the EU research and innovation policy landscape. European Commission. Available at http://ec.europa.eu/regional_policy/sources/docgener/brochure/smart/role_smartspecialisation_ri.pdf

Georges, A., Schuurman, D., Baccarne, B., \& Coorevits, L. (2015). User engagement in living lab field trials. info, 17(4), 26-39.

Gianelle, C., Kyriakou, D., Cohen, C. and Przeor, M. (2016). Implementing Smart Specialisation: A Handbook, Brussels: European Commission, EUR 28053 EN, DOI:10.2791/53569

Giovannella, C. (2013, August). "Territorial smartness" and emergent behaviors. In 2nd International Conference on Systems and Computer Science (pp. 170-176). IEEE.

Griniece, E., León, L.R., Reid, A., Komninos, N., Panori, A. (2017). D1.2: State of the art report on methodologies and online tools for smart specialisation strategies. Online S3 project, https://www.onlines3.eu/

Hinings, B., Gegenhuber, T., \& Greenwood, R. (2018). Digital innovation and transformation: An institutional perspective. Information and Organization, 28(1), 52-61.

Jaruzelski, B., J. Loehr, and R. Holman (2013). The global innovation 1000: Navigating the digital future. Business and Strategy, 73, 33-45.

Karimi, S., Papamichail, K. N., \& Holland, C. P. (2015). The effect of prior knowledge and decision-making style on the online purchase decision-making process: A typology of consumer shopping behaviour. Decision Support Systems, 77, 137-147.

Kitchin, R. (2014). Big Data, new epistemologies and paradigm shifts. Big Data \& Society, 1(1), 2053951714528481

Kleibrink, A. and Edurne, M. (2018). The making of responsive innovation policies: varieties of evidence and their contestation in the Basque Country. Palgrave Communications, 4(74). DOI: https://doi.org/10.1057/s41599-018-0136-2

Komninos, N. (2019). Smart Cities and Connected Intelligence: Platforms, ecosystems and network effects. Routledge.

Komninos, N. (2018). Architectures of Intelligence in Smart Cities: Pathways to problem-solving and innovation. ArchiDOCT, 6(1), pp. 17-35.

Komninos, N. (2014). The Age of Intelligent Cities: Smart environments and innovation-for-all strategies. Routledge.

Komninos, N. (2013). Intelligent cities: innovation, knowledge systems and digital spaces. Routledge.

Komninos, N. (2008). Intelligent cities and globalisation of innovation networks. London and New York: Routledge.

Komninos, N., and Mora, L. (2018). Exploring the Big Picture of Smart City Research. Scienze Regionali: Italian Journal of Regional Science, 1(2018), 15-38.

Komninos, N., and Panori, A. (2019). The creation of city smartness: Architectures of intelligence in smart cities and smart ecosystems. In: Smart Cities in the Post-algorithmic Era: Integrating technologies, platforms and governance. Edward Elgar.

Komninos, N., Kakderi, C., Panori, A., Garcia, E., Fellnhofer, K., Reid, A., Cvijanović, V., Roman, M., Deakin, M., Mora, L., \& Reid, A. (2018). Intelligence and Co-creation in Smart Specialisation Strategies: Towards the Next Stage of RIS3. White Paper. https://www.onlines3.eu/results. Accessed 10.08.2018. 
Komninos, N., Kakderi, C., Panori, A., \& Tsarchopoulos, P. (2018). Smart City planning from an evolutionary perspective. Journal of Urban Technology, 1-18

Komninos, N., Musyck, B., and Reid, A. (2014a). Smart specialisation strategies in south Europe during crisis. European Journal of Innovation Management, 17(4), 448-471. DOI: https://doi.org/10.1108/EJIM-11-2013-0118

Kummitha, R. K. R., \& Crutzen, N. (2017). How do we understand smart cities? An evolutionary perspective. Cities, 67, 43-52.

Landabaso, M. (2014). Guest editorial on research and innovation strategies for smart specialisation in Europe: Theory and practice of new innovation policy approaches. European Journal of Innovation Management 17(4), 378-389.

Langlois, G., and Elmer, G., (2013). The research politics of social media platforms. Culture Machine, 14. Lund, A. M. (2001). Measuring usability with the use questionnaire12. Usability interface, 8(2), 3-6.

Mahyar, N., Kim, S. H., \& Kwon, B. C. (2015, October). Towards a taxonomy for evaluating user engagement in information visualization. In Workshop on Personal Visualization: Exploring Everyday Life (Vol. 3, p. 2).

Marianelli, E., and Perinez Forte, I. (2017). Smart Specialisation at work: The entrepreneurial discovery as a continuous process. JRC technical reports, S3 Working Paper Series No. 12/2017. Publications office of the European Union: Luxemburg.

Mazzucato, M. (2018). Mission-Oriented Research \& Innovation in the European Union: A problemsolving approach to fuel innovation-led growth. Brussels: European Commission.

Mehr, H., Ash, H., \& Fellow, D. (2017). Artificial intelligence for citizen services and government. Ash Cent. Democr. Gov. Innov. Harvard Kennedy Sch., no. August, 1-12.

Moore, W. L., \& Lehmann, D. R. (1980). Individual differences in search behavior for a nondurable. Journal of consumer research, 7(3), 296-307.

Mora, L., Bolici, R., and Deakin, M. (2017). The First Two Decades of Smart-City Research: A Bibliometric Analysis. Journal of Urban Technology, 24(1), 3-27.

Mora, L., Deakin, M., \& Reid, A. (2019a). Combining Co-Citation Clustering and Text-Based Analysis to Reveal the Main Development Paths of Smart Cities. Technological Forecasting and Social Change, 142, 56-69.

Mora, L., Deakin, M., \& Reid, A. (2019b). Strategic Principles for Smart City Development: A Multiple Case Study Analysis of European Best Practices. Technological Forecasting and Social Change, 142, 70-97.

Mora, L., \& Deakin, M. (2019). Untangling Smart Cities: From Utopian Dreams to Innovation Systems for a Technology-Enabled Urban Sustainability. Amsterdam: Elsevier.

Mora, L., and Bolici, R. (2016). The Development Process of Smart City Strategies: The Case of Barcelona. In J. Rajaniemi (Ed.), Re-city: Future City - Combining Disciplines (pp. 155-181). Tampere: Juvenes print.

Mora, L., and Bolici, R. (2017). How to Become a Smart City: Learning from Amsterdam. In A. Bisello, D. Vettorato, R. Stephens, and P. Elisei (Eds.), Smart and Sustainable Planning for Cities and Regions: Results of SSPCR 2015 (pp. 251-266). Cham: Springer

Nachira, F., Dini, P., \& Nicolai, A. (2007). A network of digital business ecosystems for Europe: roots, processes and perspectives. European Commission, Brussels, Introductory Paper, 106.

Nambisan, S., Lyytinen, K., Majchrzak, A., \& Song, M. (2017). Digital Innovation Management: Reinventing innovation management research in a digital world. Mis Quarterly, 41(1).

Nelson, R.S. (ed.) (1993). National Innovation Systems: A Comparative Analysis. Oxford University Press.

Nelson, R.S., and Winters, S.D. (1982). An Evolutionary Theory of Economic Change. Harvard University Press.

Oh, D. S., Phillips, F., Park, S., \& Lee, E. (2016). Innovation ecosystems: A critical examination. Technovation, 54, 1-6. 
Panori, A., González-Quel, A., Tavares, M., Simitopoulos, D., and Arroyo, J. (2016). Migration of applications to the Cloud: A user-driven approach. Journal of Smart Cities, 2(1). DOI: http://dx.doi.org/10.18063/JSC.2016.01.005

Panori, A., Komninos, N., Kakderi, C., \& Fellnhofer, K. (2017). Smart Specialisation Strategies: An Online Platform for Strategy Design and Assessment. In International Conference on Reliability and Statistics in Transportation and Communication (pp. 3-16). Springer, Cham.

Panori, A., Angelidou, M., Mora, L., Reid, A. and Sefertzi, E. (2018). Online platforms for Smart Specialisation Strategy and Smart Growth. In proceedings, 20th Scientific Conference Association of Greek Regional Scientists, Regions at a turning point: Post-Digital communities, New regionalism and Re-nationalisation - Sustainable development implications, Athens 2018, pp. 96-102.

Piatkowski, M., Wolszczak, G., Toborowicz, J., Sacha, W., Haven, T., Klupa, A., ... \& Perek-Bialas, J. (2016). Toward an Innovative Poland: The Entrepreneurial Discovery Process and Business Needs Analysis. Report. World Bank.

Piller, F., \& West, J. (2014). Firms, users, and innovation. New frontiers in open innovation, 29(1).

Qi, G. J., Aggarwal, C. C., Han, J., \& Huang, T. (2013). Mining collective intelligence in diverse groups. In Proceedings of the 22nd international conference on World Wide Web (pp. 1041-1052). ACM.

Radjou, N., Cameron, B., Kinikin, E., \& Herbert, L. (2004). Innovation networks. A new market structure will revitalize invention-to-innovation cycles. Forrester Research.

Radosevic, S. (2017). Assessing EU smart specialization policy in a comparative perspective. In S. Radosevic, A. Curaj, R. Gheorghiu, L. Andreescu and I. Wade (eds.) (2017), Advances in the Theory and Practice of Smart Specialization, London: Academic Press, pp. 1-36

Reid, A., Maroulis, N., (2017). From Strategy to Implementation: The Real Challenge for Smart Specialization Policy. In Advances in the Theory and Practice of Smart Specialization. Academic Press, pp. 293-318.

Rojas Pino, L. A., \& Macías, J. A. (2013). Bridging the gap between information architecture analysis and software engineering in interactive web application development. Science of Computer Programming.

Rodriguez-Pose, A., and Wilkie, C., (2017). Institutions and the entrepreneurial discovery process for smart specialization. In Governing Smart Specialisation, Kyriakou, D., Palazuelos Martinez, M., PeriáñezForte, I. and Rainoldi, A. (eds.), London, UK: Routledge.

Rowe, G., \& Frewer, L. J. (2004). Evaluating public-participation exercises: a research agenda. Science, technology, \& human values, 29(4), 512-556. DOI: https://doi.org/10.1177\%2F0162243903259197

Rowe, G., \& Frewer, L. J. (2005). A typology of public engagement mechanisms. Science, Technology, \& Human Values, 30(2), 251-290.

Sanders, E. B. N., \& Stappers, P. J. (2008). Co-creation and the new landscapes of design. Co-design, 4(1), 5-18.

Schaffers, H., Komninos, N., Pallot, M., Trousse, B., Nilsson, M., \& Oliveira, A. (2011). Smart cities and the future internet: Towards cooperation frameworks for open innovation. In The future internet assembly (pp. 431-446). Springer, Berlin, Heidelberg.

Scherer, F. M. (1986). Innovation and growth: Schumpeterian perspectives. MIT Press Books.

Schmidt, J. B., \& Spreng, R. A. (1996). A proposed model of external consumer information search. Journal of the academy of Marketing Science, 24(3), 246-256.

Schwarz, A. J. (2016). Platform logic: The need for an interdisciplinary approach to the platform-based economy. IPP2016, 22-23.

Seltzer, E., \& Mahmoudi, D. (2013). Citizen participation, open innovation, and crowdsourcing: Challenges and opportunities for planning. Journal of Planning Literature, 28(1), 3-18.

Sharma, A. (2010). Crowdsourcing Critical Success Factor Model: Strategies to harness the collective intelligence of the crowd. London School of Economics (LSE), London.

Song, G., Zhang, N., \& Meng, Q. (2009). Innovation 2.0 as a Paradigm Shift: Comparative Analysis of Three Innovation Modes. In 2009 International Conference on Management and Service Science (pp. 1-5). IEEE. 
Streitz, N. (2017). Reconciling humans and technology: the role of ambient intelligence. In European Conference on Ambient Intelligence (pp. 1-16). Springer, Cham.

Susha, I., Grönlund, ^̊., \& Janssen, M. (2015). Organizational measures to stimulate user engagement with open data. Transforming Government: People, Process and Policy, 9(2), 181-206.

Svahn, F., \& Henfridsson, O. (2012). The dual regimes of digital innovation management. In 45th Hawaii International Conference on System Sciences (pp. 3347-3356). IEEE.

Tabacchi, M. E., Portmann, E., Seising, R., \& Habenstein, A. (2019). Designing Cognitive Cities. In Designing Cognitive Cities (pp. 3-27). Springer, Cham.

Tang, J., Kacmar, K. M. M., \& Busenitz, L. (2012). Entrepreneurial alertness in the pursuit of new opportunities. Journal of Business Venturing, 27(1), 77-94.

Tukiainen, T., Leminen, S., \& Westerlund, M. (2015). Cities as collaborative innovation platforms.

Van Dijck, J., (2013). The Culture of Connectivity: A Critical History of Social Media. New York, Oxford University Press.

Walsh, J.N. (2014). The sharing and transfer of context specific knowledge in a product support environment. International Journal of Knowledge-Based Development, 2014 Vol.5, No.1, 80 - 97.

Wu, D., Rosen, D. W., Wang, L., \& Schaefer, D. (2015). Cloud-based design and manufacturing: A new paradigm in digital manufacturing and design innovation. Computer-Aided Design, 59, 1-14.

Yoo, Y. (2012). The tables have turned: How can the information systems field contribute to technology and innovation management research? Journal of the Association for Information Systems, 14(5), 4.

Yoo, Y., Boland Jr, R. J., Lyytinen, K., \& Majchrzak, A. (2012). Organizing for innovation in the digitized world. Organization science, 23(5), 1398-1408.

Yoo, Y., Henfridsson, O., \& Lyytinen, K. (2010). Research commentary-the new organizing logic of digital innovation: an agenda for information systems research. Information systems research, 21(4), 724-735. 